

\section{WAIKATO JOURNAL OF EDUCATION}

Te Hautaka Mātauranga o Waikato

VOLUME 5, 1999

Vouchers and the Privatisation of New Zealand Education

LIZ ELEY AND JOHN CLARK

Standards-based Assessment in English: Take 3

TERRY LOCKE

Poem: Untitled

PIRKKO MARKULA

Qualifications, Critiques, and Reforms: The Rhetoric Surrounding

the New Zealand Qualifications Authority

IVAN HODGETTS AND DARRIN HODGETTS

Poem: Boarder's Leave Ending

RACHEL WOOD

The Maori Language Science Curriculum in Aotearoa/New

Zealand: A Contribution to Sustainable Development

MILES BARKER

SPECIAL SECTION: TEACHER EDUCATION AND TEACHING:

Introduction

BARBARA HAROLD

Reviews of Teacher Education in New Zealand 1950-1998:

Continuity, Contexts and Change

NOELINE ALCORN

Research Trends and Possibilities in Teacher Education

CLIVE MCGEE

Teachers Talk Back: Educational Theory and Teacher Education

SUE MIDDLETON AND HELEN MAY

Stories to Live by on the Professional Knowledge Landscape

D. JEAN CLANDININ

Remapping the Practicum in Teacher Education

ROSIE LE CORNU (DOBBINS) 
The Effectiveness of a Māori-Focussed Teacher Education

Programme

FRED KANA

Poem: Day is Done

138

TERRY LOCKE

Coping with the Dual Crises of Legitimation and Representation

in Research

RICHARD PRINGLE

Poem: Tracks

151

JIM DENISON

Bright Future, Five Steps Ahead - Making Ideas Work for New

Zealand: A Commentary

HOWARD LEE AND GREGORY LEE

Ka Ora Kāinga Rua: Finding a Home in the Academy. A study

into the Experiences of Four Maori Women in the Academy

LAURA HAWKSWORTH AND PARE KANA

Neo-Liberalism and Constructions of Democracy:

The Impact on Teachers' Work

NESTA DEVINE

Producing an "Iwi-Meaningful" Doctoral Proposal:

181

A Case Study

BELLA TE AKU GRAHAM

"Coming to Know" in Teaching Physical Education:

189

Moving Across Cultural Boundaries

GEORGE SALTER

To the Fullest Extent of his Powers: C.E. Beeby's Life in Education

199

NOELINE ALCORN

Poem: Junia

208

DEBORAH FRASER

Poem: Tania

209

DEBORAH FRASER

Poem: Otorohanga, 1966

DEBORAH FRASER

Book Reviews

Poem: Let's Hear It

TERRY LOCKE 


\title{
"COMING TO KNOW" IN TEACHING PHYSICAL EDUCATION: MOVING ACROSS CULTURAL BOUNDARIES
}

\author{
GEORGE SALTER \\ Department of Social, Physical and Health Education \\ University of Waikato
}

\begin{abstract}
This article explores a number of methodological and procedural issues surrounding research across cultural and gender boundaries. The research involves narrative inquiry in one collaborative Kaupapa Māori context, exploring the experiences of mature-aged Maori women teachers as they implement the new health and physical education curriculum in their schools. Their construction of meaning is informed by both western and traditional Māori world views, at times leading to contradiction and conflict. The process whereby the participants story and re-story their personal narratives in "coming to know" how to teach physical education illustrates other ways of knowing. Research issues related to initiation, benefits, representation, legitimation and accountability are addressed through a collaboratively negotiated research agenda sensitive to Māori cultural aspirations, practices and preferences.
\end{abstract}

\section{INTRODUCTION}

... to know something is not just to have received information, but also to have interpreted and related it to other knowledge (Resnick and Clopfer, 1992, p. 4).

This article is a brief account of an research into the experiences of three mature-aged Māori women teachers attempting to implement the new Health and Physical Education (HPE) Curriculum (Ministry of Education, 1999) in their primary schools in culturally responsive ways. The focus of their work with students was the development of values and attitudes through a variety of student-centred teaching approaches within a range of innovative curriculum strategies that addressed individual learning styles (see Salter, 1999). Over time, the research project evolved for the participants into a multilayered and complex whāriki of different ways of "coming to know" the processes of teaching and learning, the subject matter, the meaning of health and well-being and the values and attitudes inscribed in two world views. It became clear that "being Māori" was embedded in the sense they made from their lived experiences, and was an important construct in the ways that they negotiated meaning in learning to teach health and physical education. While the HPE curriculum itself may have contained information in the sense suggested above by Resnick and Clopfer (1992), the other knowledge to which 
the research participants related it, and through which it was interpreted and understood, was certainly informed by a Māori epistemology and ontology which might well have been outside the conceptual framework of the curriculum. Below I explore some of the important elements underpinning our research, and highlight some of the potential problems encountered in the research process.

\section{METHODOLOGICAL CONSIDERATIONS}

\section{Kaupapa Māori Research}

The narrative inquiry methodology used in this study is located within a Kaupapa Māori research framework, a process directed specifically at selfdetermination and described by Linda Tuhiwai Smith $(1999$, p. 183) as:

... providing a focus through which Māori people, as communities of the researched and as new communities of the researchers, have been able to engage in a dialogue about setting new directions for the priorities, policies and practices for, by and with Māori.

Bishop (1996) suggests that Kaupapa Māori research involving Māori knowledge and people needs to be conducted in culturally appropriate ways that fit Māori cultural preferences, practices and aspirations in order to ". . . develop and acknowledge existing culturally appropriate approaches in the method, practice and organisation of the research" (Smith, 1992, p. 9). Often Kaupapa Māori research operates within the metaphoric construct of the whānau (after Metge, 1990). Although this term has traditionally applied to a grouping of related family members, it is used in this context to signify a collection of individuals who have come together with a common purpose, and with a commitment to adhere to a common kaupapa (agenda) in the pursuit of its aims. This "whannau of interest" (after Bishop, 1996) is the specific site in which research is shaped, carried out, analysed and disseminated (Irwin, 1994), and is an important vehicle for negotiating ethical procedures and debating issues associated with power-sharing and self-determination.

\section{Stories and Storying: Narrative Inquiry Research}

Narrative inquiry is an approach which Bishop (1996) suggests addresses Māori people's concerns about research in their lives, by recognising that all involved in the process are "participants with meaningful experiences, concerns and questions" (Connelly \& Clandinin, 1990, p. 2). In exploring the knowledge of the researchers in this study (the act of uncovering and co-constructing their own stories), I made use of a number of inter-related qualitative methodological approaches, which relied heavily as a starting point on what Haig-Brown (1992, p. 105) and Bishop (1996, p. 31) describe as "interviews as chat". These interviews were close to everyday conversations within on-going relationships, providing both myself and the co-researchers with opportunities 
to follow up or to revisit topics in the on-going construction and reconstruction of narratives.

I used a narrative inquiry approach not only because there are in any case strong cultural preferences among Māori for narrative, but because storytelling itself allows research participants to ". . . select, recollect and reflect on stories within their own cultural context and language rather than in the cultural context and language of the researcher" (Bishop, 1996, p. 24). People construct stories to understand and make sense out of their experiences, and in that process emphasise certain experiences at the expense of others in order to maintain the coherence of their storyline. Although individuals put their own stories together, people within a culture or group tend to share a dominant set of discourses, an agreed-to and more-or-less coherent set of stories about the way the world should be. Some accounts dominate and others are less often heard, and new meanings and subjective positions are negotiated constantly as different discourses collide or conflict. That our narrative inquiry was embedded in the protocols of a Kaupapa Māori framewok suggests that the power to define and control what counted as knowledge" or truth resided with the research participants rather than with myself as researcher.

\section{Writing Myself in the Story}

... speaking to and for the interests of silenced groups that one is not a member of, raises a number of ethical and pedagogical problems which operate in tandem to deter many who have positions of relative power and privilege from taking action to fracture a range of silences (Sparkes, 1997, p. 25).

As a Pākehā male I am "other" in relation to the lived Māori world of my coresearchers. Although for many years I have immersed myself in traditional Māori customs, beliefs and attitudes, I relate to Rose Pere's frustration at what she describes as the ". . . hermeneutic difficulty of expressing the concepts of one culture in the language of another" (Pere, 1988, p. 14). A barrier to my own understanding of both traditional (pre-colonisation) cultural practices, and those which have changed since Pākehā arrival, is that most accounts of structural and historical phenomena have been ". . Pākehā ideas . . . used to make observations and judgements about the Māori world with little or no attempt to reconcile the different epistemological bases of the two cultures" (Irwin, 1992, p. 8).

Assertions such as these cause me to proceed very tentatively in my own other-cultural explorations. What I describe below should therefore be read as my attempt to express some of my own understandings of a Māori world view, and in that I am speaking for myself rather than speaking for Māori. In moving from a position of "researcher as tuakana" in traditional settings to a position of "researcher as teina" in the research group, I have become as Bishop (1996) suggests "a participant in a context where power and control are located in the collective and where knowledge is created, gathered and processed for the benefit of the collective" (p. 214). My own position is congruent with those of the co-researchers, and implies connectedness, engagement, and involvement 
with them within their own cultural world view in ways that Heshusius (1994) describes as "participatory consciousness". This results in a re-ordering of the relationship between the knower and what is known, between self and other, and between self and the world, and leads to what she identifies as a "recognition of the deeper kinship between ourselves and others" (p. 15).

Below I briefly foreground some of the epistemological, methodological and procedural problems involved with researching across cultural boundaries, and discuss ways that I have attempted to address those through the protocols of Kaupapa Māori research.

\section{FRAMING THE RESEARCH PROBLEMS}

The gap between engaging others where they are, and representing them where they aren't, always immense but not much noticed, has suddenly become extremely visible. What was once technically difficult, getting their lives into our works, has turned morally, politically, even epistemologically delicate (Geertz, 1988, p. 130).

I am aware that my own domination might influence both my participation and the reporting of our co-constructed stories even in this sort of collaborative research. It is clearly problematic to involve the white western male in me to explain how I understand the role of patriarchy and gender politics, or what Gramsci (1977) might describe as the colonisation of Māori minds, in the process of my co-researchers constructing knowledge for teaching physical education. I am sensitive to the "them" and "us" constructs alluded to by Geertz (1988) above, and I support Bishop's (1994) assertion that Māori and non-Māori alike need to reposition themselves in relation to the aspirations of Māori people for an autonomous voice. In more traditional discourses, significations of difference between myself and my co-researchers (for example, male-female, Pākehā-Māori, teacher-student and researcher-researched relationships) might potentially constitute power differentials which I believe our adherence to Kaupapa Māori protocols has successfully undermined.

As Bishop (1996, p. 42) suggests, explanations from within the dominant discourse highlight the tension of working within an academic institution predicated on one world view - a view in which my own biography is deeply embedded - and carrying out research which is supposedly culturally safe, relevant and appropriate from another world view. My experience is that theoretical and methodological issues are addressed in the ongoing processes of Kaupapa Māori research itself. Below I highlight several of these issues, and ways I have attempted to address them. The sub-headings I use and the questions to be asked under each are suggested by Bishop (1996, p. 22), and have served as a useful focus in negotiating the collaboratively agreed agenda of the research project.

\section{Initiation}

The Māori women who are members of the research whānau had originally been my off-campus students in physical education and outdoor education 
curriculum courses. Over the five years since we first worked together, they have become close friends and whaea (mothers) within my own family. My wife has connections through whakapapa (geneaology) so they really are whanaunga (relatives) in a Māori sense. We have worked well together in several small collaborative curriculum development projects, and are able to draw on the strengths and knowledge of each person as the need arises without myself constantly being positioned as leader.

Our mutual passion and the starting point for the curriculum project was the teaching of te reo kori (the Māori dimension of movement) in physical education, as a vehicle for promoting identity and self-worth (see Salter, 1998). It became increasingly clear that we could only make sense of our current experiences through exploring our own stories. Through narrative inquiry we began to explore the complexities of how being Māori, mature-aged and so on, meant that one brought particular skills and knowledge to teaching physical education which might be different from those brought by others. The stories seemed to emerge by themselves as an integral part of the curriculum project, with mauri (life force) of their own.

The focus of the curriculum project was provided by our desire to address learning needs of Māori students in mainstream education. Over time, this project became almost peripheral to our individual and collective curiosity about working across cultural boundaries - for each of us, a matter of, "Where can I locate myself in these stories?" Some of our ensuing interviews were conducted and tape-recorded individually, often taking the form of interviews as chat, and sometimes the group came together and shared thoughts and stories. At different times, one member of the group would seemingly steer the inquiry, and at other times what seemed to be an idle comment would send discussion at tangents as ideas were triggered and built on. The significant point about the agenda of the research was that it arose within the group, was agreed to either overtly or tacitly, and responded to the needs and interests of the members.

Our exploration was never linear, in that we would often cover known ground, sometimes on many occasions. Each revisit seemed to unearth more information, or a slightly different understanding or insight, or prompt us to explore ideas in different ways. It was clear also that the stories were never complete - for example, Mihi (names have been changed to respect confidentiality) would deliberately and playfully leave me small traps, so that I would need to telephone her to check on some anomaly in her transcript. She would say something along the lines of, "I wondered whether you would pick that up!", and then reveal more of the story in question. Similarly, Ani became so engrossed in trying to understand her parents' decisions to arrange the family's life in particular ways when she was growing up, that she rang her mother in Australia to check. Mother did not confirm Ani's understanding of the situation, so Ani then contacted her brother and sister to check their versions of the story. After a period of time, she rang and asked me to change our written version of her story, based on her new (co-constructed) reality.

This process of storying and re-storying suggests that within the collaborative Kaupapa Māori research context, power and privilege are shared among the members. We acknowledge the participatory connectedness that 
exists between members, which tends to remove the possibility of domination by an individual and gives rise to a jointly constructed agenda and mutual feelings of ownership of both the process and the co-constructed stories.

Sharing in their professional and personal lives is very common for these women. They have whakapapa links, have come to know each other really well since the beginning of their teacher education programme, and have worked together as a collaborative study group and as a circle of close friends and whanaunga since that time. The design of the research process itself is also co-constructed and therefore likely to be embraced by the participants as culturally safe and relevant. Far from any perception on my part that I should be controlling this research, I feel immensely privileged (and more than a little humbled) at being included in the private and social worlds of the research whannau members, and to be considered an equal member of that group.

\section{Benefits}

I have described above the tensions I have felt at being part of a research project that quite clearly sits outside the dominant discourse of the professional institution of which I am a member. There are similar tensions for me with regard to receiving benefits which are inscribed in a Māori world view (for example, self-growth, an increased sensitivity to tikanga Māori, the development of close relationships with other members of the research whānau, and so on), while also receiving benefits in the Pākehā education world view which my co-researchers might be denied. As I write this article I am conscious that its publication has currency in that second world for me alone (in intellectual and professional terms), and for that reason I am privileged over other members of the research whannau. Telling their stories through the collaborative research process offers them the sorts of personal and social benefits I mentioned above, but at face value offers little else.

I use the expression "at face value" here, because in discussion with professional (Pākehā) colleagues about our research, I have been asked the question, "Yes, but what's in it for them?" The answer to that question undoubtedly lies in the values and beliefs of the cultural world view of the research whānau members. They position themselves in three particular ways which encourage me to represent our collaborative efforts:

1. From a Māori perspective they see themselves clearly as kaitiaki (custodians or guardians of knowledge), rather than from a conventional (western) perspective as teachers (transmitters of information). Any deeper understanding we can all arrive at through our own stories with regards to how Māori children experience tensions and conflict within a Eurocentric schooling system is likely to impact positively on the life chances of our tamariki (i.e Māori children).

2. If through the research process itself I have personally developed greater cultural sensitivity and the motivation to adjust content and/or pedagogical processes in my teacher education courses to address the needs and enhance the success of Māori students, then this too is likely to impact positively on the Māori community. 
3. If my disseminating our stories and information about the research process itself (for example, through publications) to a wider community stimulates interest, creates greater cultural sensitivity, enhances tolerance towards other world views, or prompts another researcher to address these theoretical and methodological issues in their own work, then it may be said that we have in some small way supported the cultural aspirations of Māori.

\section{Representation}

As Bishop (1996, p. 24) suggests, story-telling in the context of this research aims to uncover the complexities and contradictions in people's lives, rather than represent an uncomplicated and generalisable truth. The social reality which our research reports on and depicts through our writing (telling) of the collaborative stories is ours alone. While others may read our work and identify with some experiences or explanations, we make no claim to be speaking for all Māori, or for other groups who might be tribally, geographically, generationally, or otherwise positioned. I addressed some important philosophical and ethical concerns about representation above, and indicated that the Kaupapa Māori research process adequately addresses concerns of setting research questions, allocating tasks, determining whose voice is heard, and so on. It does this by recognising that everyone involved in the process is a full participant, not just an informant, with their own strengths and experiences, and with their own equally valid stories to tell.

A final comment about representation concerns the notion of how the research findings are made public. As well as my publications or conference presentations being a way of disseminating information, it is seen by the research whānau and by the Māori community at large to be far more culturally appropriate to share knowledge though hui. Through following traditional protocol at such a gathering, particularly in view of my own comparatively low level of linguistic competence (I am teina in that setting) it is clear that power is shared and the principles of tino Rangatiratanga are promoted.

\section{Legitimation}

Working across the boundaries of two world views can create conflicts, contradictions and tensions, as I have suggested. The formal legitimation requirements of the research - for example, approval from the University Ethics Committee to use human subjects, obtaining written consent, and so on - have been adhered to. It must be said, however, that the research whānau regards itself as autonomous in deciding who will process the data, what happens to the results, and so on. The Kaupapa Māori research process solves these sorts of dilemmas by encouraging the incorporation of ethical procedures, and promoting the debate of issues associated with the research. The protocols themselves perform a sort of quality control function and bestow a mutually agreed legitimacy through power-sharing and self-determination. The stories themselves are co-constructed, which implies whannau sanction and definition as to what is regarded as accurate, true and complete in the texts. 
While I personally might do the work of theorising the research and actually committing the stories to paper (I am regarded as tuakana in this, these are particular skills which I bring to the collaborative effort), the meanings within the stories are always mutually agreed co-constructions, and as such represent the group's understandings.

I am conscious too that the construction of meaning can be problematic in itself. As both Connelly and Clandinin (1990) and Bishop (1996) point out, it is never enough to simply listen to and record stories of experience, because it is impossible to still our theorising voices (Bishop, 1996, p. 23) as we constantly reflect and seek explanations for our own experiences in the stories of others. In this way, the telling of any story is likely to have impact on the listener in terms of prompting them to re-order their own self narratives (Giddens, 1991). The co-construction of meaning in the Kaupapa Māori research process can therefore be seen to address the problems associated with legitimacy (or otherwise) of the personal subjective voice. In my writing I always try to emphasise at which points I am speaking for myself, and at which points I am the sanctioned narrator of our co-constructed stories.

\section{Accountability}

As the researcher in this project, I am considered accountable in a number of ways by those positioned in the traditional discourse. For example, I clearly have a responsibility to any funding agency, to the University Ethics Committee, to the co-researchers themselves in ensuring authenticity and confidentiality in my report, and so on. Beyond this however, I also accept a responsibility in ensuring that the research is culturally safe and relevant, and in this I take my guidance from the other members of the research whannau, who are much more experienced and knowledgeable than I regarding matters of protocol. In my tentative early approach to the project, when we were all very much peripheral participants in the research community of practice (Lave \& Wenger, 1991), I suggested that we consider including a kaumatua in the research process. This suggestion arose from several considerations:

- I was responding to my own perceived lack of competence in a Māori world

- I wanted to ensure that culturally safe and appropriate protocols were followed

- I wanted our work to be seen by Māori as legitimate.

In debate it was decided that we could conduct our affairs appropriately without a kaumatua. The decision was based primarily on the fact that all the women occupy positions of prestige in their local communities and are actively involved with many traditional activities which involve adherence to tikanga Māori, and so they felt perfectly competent to address issues of cultural safety, relevance, and so on. Further, by this time we had developed such close and respectful working relationships within the research whannau - the participatory consciousness described by Heshusius (1994, p. 15) - that the mediating function of an outsider to the group was seen as an intrusion rather than a need. This is a further example of the level of power-sharing among 
group members when using Kaupapa Māori research processes. Despite this (and with the knowledge and agreement of the group), for my own part I have made sure that I discussed issues and concerns with my own tuakana, Ted Glynn and Russell Bishop, who both have extensive Kaupapa Māori research experience. This consultation process is also two-way, of course, and provides us with another challenge in foregrounding accountability in our work.

\section{CONCLUSION}

My intention in this article has been to provide a brief account of research in one Māori context, and to highlight some of the epistemological and methodological problems associated with working with groups of which one is not a member. The Kaupapa Māori collaborative research approach has shown itself in this case to be extremely powerful in generating co-constructed stories, and in helping members of the research whannau connect self-identity, their personal lived experiences from a Māori world view, and western knowledge. I too am inscribed in those stories and I feel honoured and privileged to have been granted access to the processes. I thank my research colleagues for teaching me so much.

Tūngia te ururua kia tupu whakaritorito te tupu $\bar{o}$ te harakeke

Burn the overgrowth so the flax will develop new shoots

\section{REFERENCES}

Bishop, R. (1994). Initiating empowering research. New Zealand Journal of Education Studies, 29 (1), 1-14.

Bishop, R. (1996). Whakawhanaungatanga: Collaborative Research Stories. Palmerston North, NZ: Dunmore Press.

Connelly, F.M. \& Clandinin, D.J. (1990). Stories of experience and narrative inquiry. Educational Researcher, 19 (5), 2-14.

Geertz, C. (1988). Works and Lives: The Anthropologist as Author. Cambridge: Polity Press.

Giddens, A. (1991). Modernity and Self-Identity: Self and Society in the Late Modern Age. Cambridge: Polity Press.

Gramsci, A. (1977). Selections from Political Writings (1910-1920). New York: International Publishers.

Haig-Brown, C. (1992). Choosing border work. Canadian Journal of Native Education, 19 (1), 96-115.

Heshusius, L. (1994). Freeing ourselves from objectivity: Managing subjectivity or turning toward a participatory mode of consciousness? Educational Researcher, 23 (3), 15-22.

Irwin K. (1992). Maori research methods and processes: An exploration and discussion. Paper presented at the joint New Zealand Association for 
Research in Education/Australian Association for Research in Education Conference, Geelong, Australia: November 1992.

Irwin K. (1994). Māori research methods and practices. Sites, 28, 25-43.

Lave, J. \& Wenger, E. (1991). Situated Learning: Legitimate Peripheral Participation. Cambridge: Cambridge University Press.

Metge, J. (1990). Te rito o te harakeke: Conceptions of the whānau. Journal of the Polynesian Society, 99 (1), 55-92.

Ministry of Education (1999). Health and Physical Education in the New Zealand Curriculum. Wellington, NZ: Learning Media.

Pere, R.R. (1988). Te wheke: Whaia te maramatanga me te aroha. In S. Middleton (Ed.), Women and Education in Aotearoa. Wellington, New Zealand: Allen and Unwin.

Resnick, L.B. \& Clopfer, L.E. (1992). Toward the thinking curriculum: An overview. In L.B. Resnick \& L.E. Clopfer (eds.), Toward the Thinking Curriculum: Current Cognitive Research (pp. 1-18). Association for Supervision and Curriculum Development.

Salter, D.G. (1998). Me ako ki ngā tikanga Māori i te reo kori: Culture and learning through te reo kori. Journal of Physical Education New Zealand, 31 (1), 18-21.

Salter, D.G. (1999). Unfolding attitudes and values in physical education: Stretching the limits of traditional pedagogy. Teachers and Curriculum, 3 (in press).

Smith, G. H. (1992). Tane Nui a Rangi's legacy . . . propping up the sky: Kaupapa Māori as resistance and intervention. Paper presented at the joint New Zealand Association for Research in Education/Australian Association for Research in Education Conference, Geelong, Australia: November 1992.

Smith, L.T. (1999). Decolonizing Methodologies: Research and Indigenous Peoples. Dunedin, NZ: University of Otago Press.

Sparkes, A.C. (1997). Ethnographic fiction and representing the absent other. Sport, Education and Society, 2 (1), 25-40. 